\title{
Low levels of genetic differentiation among populations of the freshwater fish Hypseleotris compressa (Gobiidae: Eleotridinae): implications for its biology, population connectivity and history
}

\author{
DUGALD J. McGLASHAN \& JANE M. HUGHES* \\ Co-operative Research Centre for Tropical Rainforest Ecology and Management, \\ Australian School of Environmental Studies, Griffith University, Nathan, Queensland, Australia, 4111
}

\begin{abstract}
The isolating nature of freshwater systems may lead to expectations of substantial genetic subdivision among populations of obligate freshwater species. We examined the genetic structure of populations of the freshwater fish Hypseleotris compressa (Gobiidae) using allozyme and mtDNA markers. Fifteen east coast Queensland populations and one Northern Territory population were sampled to examine levels of differentiation within and between drainages at near, medium and broad scales. Initial allozyme data suggested high levels of gene flow and connectivity among populations at broad spatial scales. However there was no significant relationship between geographical distance and gene flow among east coast populations which may indicate, among other possibilities, that these populations are not at equilibrium between gene flow and genetic drift. Analyses of a 567-bp fragment of the ATPase6 mtDNA gene revealed a star-shaped phylogeny, with many singleton, recently derived haplotypes. Tajima's test of neutrality was significantly negative. The allozyme and mtDNA data may be indicative of an historical demographic change that was reflected in the nonequilibrium pattern exhibited by contemporary populations. As estimating current levels of gene flow would violate basic assumptions of underlying models, approximations were not made. Nevertheless, patterns of genetic variation among populations of $H$. compressa do not match traditional expectations for a freshwater fish, and it would appear that there has been at least historical connectivity between populations now inhabiting different drainages.
\end{abstract}

Keywords: allozymes, dispersal capability, freshwater fish, gene flow, mitochondrial DNA, nonequilibrium.

\section{Introduction}

Freshwater fishes tend to exhibit higher levels of genetic differentiation and subdivision among populations than those inhabiting estuarine or marine environments (Gyllensten, 1985; Ward et al., 1994). The differences in the distribution of genetic variability between freshwater and marine fish have been attributed to differences in population sizes and to geographical barriers among freshwater localities, which isolate populations (Gyllensten, 1985; Ward et al., 1994). However, even in the marine environment examples of extreme differentiation have been discovered (e.g. Doherty et al., 1994; Burton,

*Correspondence. E-mail: Jane.Hughes@mailbox.gu.edu.au
1998). Estuaries and islands also appear to act as foci for divergence in many marine species (e.g. Watts, 1991; Johnson \& Black, 1998).

Few genetic studies have examined the population structure of Australian freshwater fish that inhabit lowland coastal streams; most have concentrated on examining populations inhabiting inland drainages or those that are separated by barriers such as ranges (e.g. Musyl \& Keenan, 1992, 1996) or escarpments (Watts et al., 1995). A recent study of genetic variation among populations of the fly-specked hardyhead Craterocephalus stercusmuscarum in north Queensland found that gene flow was restricted, even between adjacent lowland drainages (McGlashan \& Hughes, 2000). In the oxleyean pygmy perch Nannoperca oxleyana high levels of 
differentiation were also found among most lowland populations, although high genetic similarities between some populations from separate drainages may have been a result of a shared confluence at times of lower sea levels (Hughes et al., 1999). Estuarine species generally exhibit less differentiation and often demonstrate patterns of isolation by distance, implying greater dispersal among nearby compared to distant estuaries (e.g. Chenoweth et al., 1998a; Jerry \& Baverstock, 1998). Genetic differentiation among populations of marine species along the east coast of Australia is generally lower than in either estuarine or freshwater species, which implies that gene flow is more extensive (e.g. Doherty et al., 1995; Begg et al., 1998). However, historical isolation followed by secondary contact or recolonization associated with Pleistocene sea level changes have influenced patterns of genetic variation among populations of some marine species (e.g. Keenan, 1994; Chenoweth et al., 1998b).

A generally accepted model is that freshwater fish display high levels of genetic differentiation among populations from different drainages. We were interested in examining if this model was supported in a species which has the dispersal potential that may overcome the isolation imposed by drainage structure. According to available life history data, the empire gudgeon Hypseleotris compressa (Krefft) (Gobiidae: Eleotridinae) is a good test organism. Fecundity is high ( 40000$)$ and egg diameter is small $(0.3 \mathrm{~mm})$, although the eggs are demersal and adherent (Auty, 1978). Newly hatched larvae are able to swim actively, but are poorly developed (Auty, 1978). Hypseleotris compressa has a widespread distribution across northern Australia from mid-Western Australia to southern New South Wales, and is also found in the southern drainages of New Guinea (Allen, 1989). Eleotrids may have a recent marine ancestry, like many of Australia's freshwater fish (Allen, 1989).

The level of connectivity of populations among drainages is largely unknown, but may be high within rivers. For example, schools of juveniles are often found in estuaries (Larson \& Hoese, 1996) and anecdotal reports suggest that large numbers migrate upstream after rain (Herbert et al., 1995). Adults are generally found in downstream areas near river mouths, although they do penetrate far upstream (Pusey and Kennard, unpublished data and personal observation). Tolerance to elevated salinities is implied by the fact that $H$. compressa have been captured from intermittent tidal swamps (Robertson \& Blaber, 1992). There are three scenarios which may describe the levels of gene flow among populations of $H$. compressa: (i) gene flow among drainages has been negligible for long periods resulting in genetic differentiation among drainages; (ii) there has been some gene flow among drainages facilitated by marine routes such as via fresh water plumes, but is limited at larger scales (isolation by distance); or (iii) there is, or has been, extensive gene flow resulting in little genetic differentiation among drainages and no phylogeographic structure. An ideal way to test this is with allozyme electrophoresis and mitochondrial DNA techniques, demonstrated to be extremely useful in assessing population structure, levels of connectivity and influence of historical processes (see Avise, 1994). We used these techniques to examine patterns of genetic variation among populations of $H$. compressa from a large section of their range.

\section{Methods and materials}

\section{Sampling}

Sampling followed an hierarchical design to assess genetic variation within and among drainages. Five sites within the Mulgrave-Russell River and three sites within the Johnstone River were analysed to obtain an estimate of allozyme variation among populations within a drainage (Fig. 1). To assess allozyme variation among drainages, samples of $H$. compressa from an additional seven drainages were collected along the Queensland coast, and one sample from the Northern Territory (Fig. 1). In total we analysed 571 fish from 16 sites and 10 drainages, which were collected between May 1996 and October 1998 (Table 1). To assess mtDNA variation, three randomly chosen individuals were sequenced from each of the 10 drainages. When there were multiple sites within a drainage, fish were randomly selected from one of the sites of that drainage. Fish were captured, preserved and stored following protocols described in McGlashan \& Hughes (2000). However, the Northern Territory population was transported on dry ice $\left(-48^{\circ} \mathrm{C}\right)$ and then transferred to a $-70^{\circ} \mathrm{C}$ freezer.

\section{Allozyme electrophoresis}

Samples were prepared and stained following the protocols of McGlashan \& Hughes (2000). Eighteen enzyme systems (see McGlashan \& Hughes, 2000) were screened to detect polymorphic loci, of which six loci encoded by four enzyme systems were reliably polymorphic. They were aspartate aminotransferase (EC 2.6.1.1; $A A T-1 * A A T-2 *$ loci), glucosephosphate isomerase (EC 5.3.1.9; GPI-1*, GPI-2* loci), phosphoglucomutase (EC 5.4.2.2; $P G M^{*}$ locus), and tripeptide aminopeptidase (EC 3.4.-.-; PEPLGG* locus) using leu-gly-gly as the substrate. Nomenclature for enzymes and loci were described in McGlashan \& Hughes (2000). 


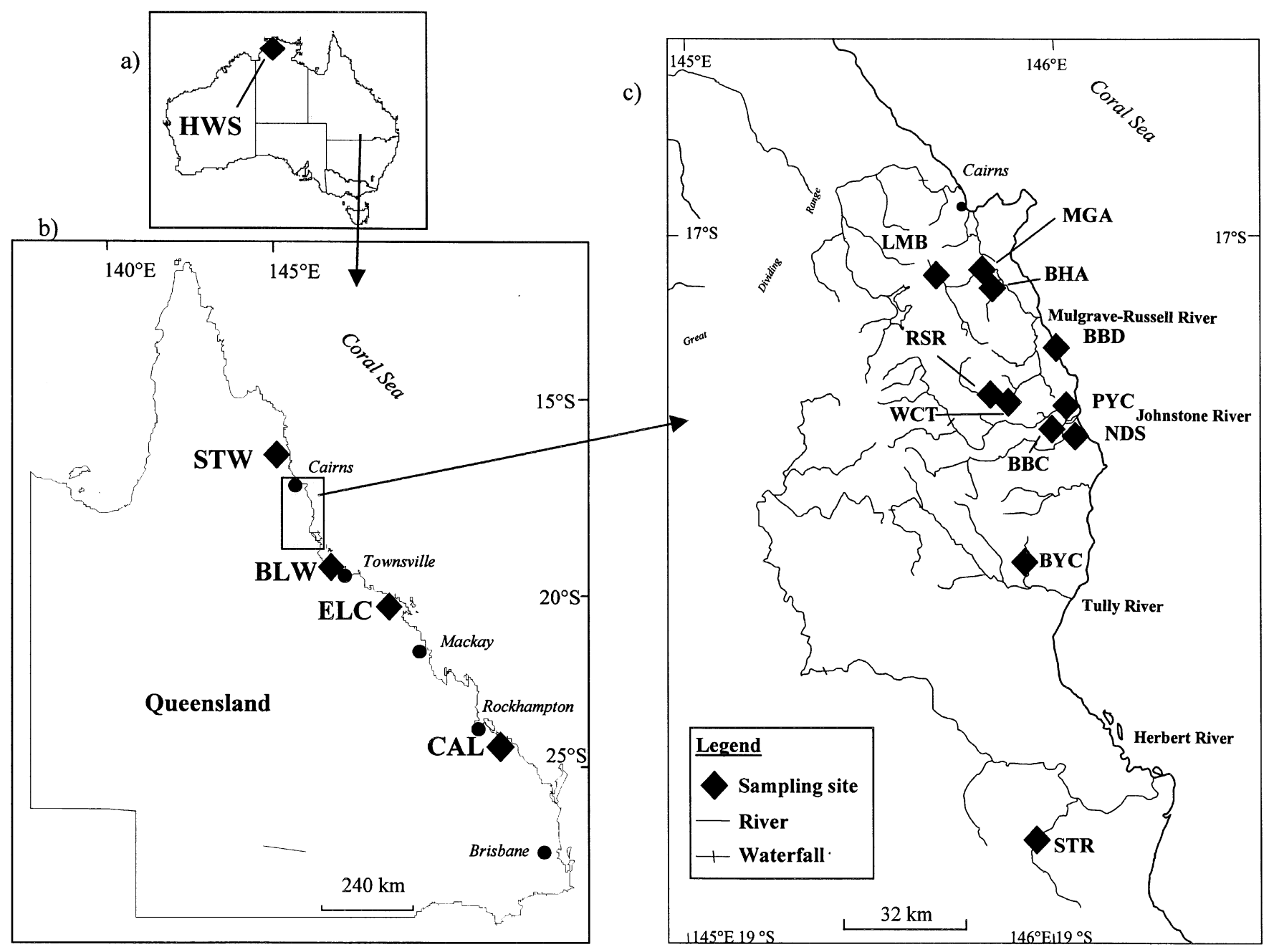

Fig. 1 Map illustrating sampling sites $(\bullet)$ of Hypseleotris compressa. For site abbreviations refer to Table 1 . Not all rivers are shown.

\section{mtDNA techniques}

Total genomic DNA was extracted following the protocols described in McGlashan \& Hughes (2000). The ATP synthase six gene was used to infer intraspecific phylogenies of $H$. compressa. This fragment has been shown to be useful in other studies of freshwater fish as it has a moderate to high divergence rate (Bermingham et al., 1997). Three fish collected over a wide geographical area were PCR amplified with the primers ATP8.2L and COIII.2 (E. Bermingham, personal communication. See web address http://nmg.si.edu/bermlab.htm for primer details). Amplification and PCR product purification procedures of the present study followed the protocols of McGlashan \& Hughes (2000). Sequences resulting from amplification with ATP8.2 and COIII.2 were used to design an internal primer HCATP6L (5'-AGC CCA CTC CTT CCC TAA CGA GC-3') which, in conjunction with COIII.2, was utilized in further PCR reactions. PCR thermocycling conditions were: ATP8.2-COIII. $294^{\circ} \mathrm{C} 30 \mathrm{~s}, 51^{\circ} \mathrm{C} 30 \mathrm{~s}, 68^{\circ} \mathrm{C} 45 \mathrm{~s}$, 35 cycles, $68^{\circ} \mathrm{C} 7 \mathrm{~min}$; HCATP6L and COIII. $294^{\circ} \mathrm{C}$ $30 \mathrm{~s}, 55^{\circ} \mathrm{C} 30 \mathrm{~s}, 68^{\circ} \mathrm{C} 45 \mathrm{~s}, 35$ cycles, $68^{\circ} \mathrm{C} 7 \mathrm{~min}$. Sequencing reactions were undertaken via cycle-sequencing (Perkin Elmer, BigDye terminator, 3.2 pmol primer, 5-20 ng DNA) using a new primer HC2L (5'-TAC TTA GGA ATC CCA CTA ATT GC- $3^{\prime}$ ) as the sequencing primer and sequenced using an Applied Biosystems 377 automated sequencer. Primer HC2L was designed internally to HCATP6L, resulting in improved final sequences. Each individual was then sequenced using heavy strand primer HCH (5'-TAC TAT GTG AAA TGC GTG TG-3') designed from the light strand primer sequences. Multiple sequences of at least three individuals were also gathered to ensure the reliability and accuracy of sequencing. SEQED (ABI) was used to edit 
Table 1 Sampling sites, drainage, geographical position and number of individuals of Hypseleotris compressa analysed for allozymes and mtDNA

\begin{tabular}{|c|c|c|c|c|c|c|c|}
\hline & Site & Abbr. & Drainage & Latitude & Longitude & $N$ allozymes & $N$ mtDNA \\
\hline 1 & Daintree R & STW & Daintree & 16.1780 & 145.1900 & 44 & 3 \\
\hline 2 & Behana $\mathrm{Ck}$ & BHB & Mulgrave-Russell & 17.0830 & 145.4995 & 44 & - \\
\hline 3 & Little Mulgrave R & LMB & Mulgrave-Russell & 17.0750 & 145.4210 & 11 & - \\
\hline 4 & Mulgrave R & MGA & Mulgrave-Russell & 17.0550 & 145.4850 & 35 & - \\
\hline 5 & Woopen Ck Tributary & WCT & Mulgrave-Russell & 17.2837 & 145.5259 & 21 & - \\
\hline 6 & Russell R & RSR & Mulgrave-Russell & 17.2700 & 145.5110 & 22 & 3 \\
\hline 7 & Bramston Beach Drain & BBD & Bramston Beach & 17.2090 & 146.0150 & 44 & 3 \\
\hline 8 & Bamboo Ck & $\mathrm{BBC}$ & (South) Johnstone & 17.3326 & 145.5975 & 42 & - \\
\hline 9 & Nind's Ck & NDS & (South) Johnstone & 17.3410 & 146.0510 & 44 & - \\
\hline 10 & Polly Ck & PYC & (North) Johnstone & 17.2862 & 146.0214 & 44 & 3 \\
\hline 11 & Banyan $\mathrm{Ck}$ & BYC & Tully & 17.5612 & 145.5556 & 33 & 3 \\
\hline 12 & Stone R & STW & Herbert & 18.3850 & 146.0210 & 44 & 3 \\
\hline 13 & Bluewater $\mathrm{Ck}$ & BLW & Bluewater & 19.1370 & 148.2880 & 32 & 3 \\
\hline 14 & Eden Lassie Ck & ELC & Eden Lassie & 20.1210 & 148.2220 & 26 & 3 \\
\hline 15 & Calliope R & CAL & Calliope & 24.1070 & 150.5800 & 41 & 3 \\
\hline 16 & Howard Springs & HWS & Howard (NT) & 12.2790 & 131.0500 & 44 & 3 \\
\hline
\end{tabular}

NT, Northern Territory.

and align sequences, of which a 567-bp fragment was chosen for further analysis.

\section{Statistical analysis}

Exact $p$-tests were performed to test for departure from Hardy-Weinberg equilibrium using GENEPOP (Raymond $\&$ Rousset, 1995a) for each locus/site comparison. The Bonferroni correction (Rice, 1989) was used to correct for multiple simultaneous tests.

Allozyme allele frequencies, Wright's (1978) hierarchical F-statistics and Rogers's (1972) genetic distance were estimated using BIosys-1 (Swofford \& Selander, 1989). Hierarchical $F$-statistics (Wright, 1978) were used to assess the variation within and among drainages. There were two levels to the hierarchical analysis that partitioned the variation among samples: among sites within a drainage $\left(F_{\mathrm{SD}}\right)$ and among drainages relative to the total $\left(F_{\mathrm{DT}}\right)$. Exact tests of differentiation (Raymond \& Rousset, 1995b) were then performed among populations within the Johnstone drainage, within the Mulgrave-Russell drainage, and among all drainages (after pooling multiple sites within a drainage) using GENEPOP (Raymond \& Rousset, 1995a). The standard error of allele frequencies was calculated for the most common allele as $\mathrm{SE}=\sqrt{ }[p(1-p) / 2 N]$ where $p$ is the allele frequency and $N$ is the sample size.

We examined how much of the observed allozyme variation among drainages was due to geographical separation following Slatkin (1993). Coastal geographical distances between drainages were plotted against pairwise values of $\widehat{M}$, estimated from $G_{\mathrm{ST}}$ of Nei (1973) (program kindly supplied by M. S. Johnson). Coastal distances were measured from 1:100 000 and 1:250 000 topographical maps using Summagraphics SummaSketch Plus software. The Daintree to Northern Territory distance was estimated from a function in the ARC/ INFO software (Environmental Systems Research Institute, USA). The significance of the relationship between $\log \widehat{M}$ and $\log$ distance was evaluated using Mantel's tests in PATN (Belbin, 1995). Ordinary least squares regression was used to estimate the slope and intercept of the line of best fit.

Pairwise nucleotide divergences among haplotypes were generated assuming the Tamura \& Nei (1993) model of substitution and rate heterogeneity. The gamma distribution parameter alpha was estimated from the data set using the PUZzLE (Strimmer \& von Haeseler, 1996) program. A mid-point rooted neighbour-joining tree (Saitou \& Nei, 1987) of unique mtDNA haplotypes was constructed in MEGA (Kumar et al., 1993) assuming the Tamura \& Nei (1993) model and the empirically derived gamma distribution parameter alpha as above. Bootstrapping was performed (1000 replicates) to test relative node support for the resulting phylogeny. An unbiased contingency test was performed to examine heterogeneity of haplotype frequencies among east coast sites. The MONTE program in REAP (McElroy et al., 1992) was used to perform this task.

Tajima's $D$-test (Tajima, 1989), which tests the conformity of DNA sequence evolution to neutrality, was performed using DNASP (Rozas \& Rozas, 1999) on sequences from east coast sites. We pooled these sequences to form one 'population', because the unbiased 


\begin{tabular}{|c|c|c|c|c|}
\hline \multicolumn{2}{|c|}{ Comparison } & \multirow[b]{2}{*}{$\sigma^{2} \mathrm{XY}$} & \multirow{2}{*}{$\begin{array}{c}\% \text { total } \\
\text { variation }\end{array}$} & \multirow[b]{2}{*}{$F_{\mathrm{XY}}$} \\
\hline $\mathrm{X}$ & Y & & & \\
\hline Within site & & 1.3017 & 98.6 & - \\
\hline Site & Drainage & 0.0196 & 1.5 & 0.015 \\
\hline Site & Total & 0.0183 & 1.4 & 0.014 \\
\hline Drainage & Total & -0.0013 & 0 & -0.001 \\
\hline \multicolumn{2}{|c|}{ Total limiting variance } & 1.3100 & 100 & - \\
\hline
\end{tabular}

Table 2 Wright's (1978) hierarchical $F$-statistics for populations of Hypseleotris compressa in the present study contingency test analysis could not reject the null hypothesis of no differentiation among east coast sites. Tajima's $D$ (Tajima, 1989) can be informative about the effects of selective events on the patterns of mtDNA variation, but also about historical demographic events on a sample of sequences (Rand, 1996). The basis of the test is that under neutrality, gene diversity, as measured by the mean number of differences between sequences in the sample $(\pi)$, should equal the gene diversity as measured by the number of segregating sites in the sample $(\theta)$.

\section{Results}

\section{Allozyme electrophoresis}

Sixteen sites were screened for allozyme variation at six polymorphic loci. Consequently, in tests of conformity to Hardy-Weinberg proportions, there were 96 possible combinations of sites and loci of which 81 were polymorphic. No tests were significant at the adjusted level of significance $(\alpha=0.05 / 81)$ after the Bonferroni correction.

Hierarchical analyses of the allozyme data reveal that the great majority of the variation is distributed within sites $(98.6 \%)$ (Table 2$)$. The variation among sites (1.4\%) was distributed as a function of the variation among sites within a drainage rather than among drainages (Table 2). Exact tests of genic differentiation showed that there was no significant variation in allele frequencies among the three Johnstone River sites $\left(\chi^{2}=9.3\right.$, d.f. $\left.=12, P=0.68\right)$ or among Mulgrave-Russell sites $\left(\chi^{2}=19.4\right.$, d.f. $=12$, $P=0.08)$. However, when all sites within a drainage were pooled there was significant heterogeneity among drainages over all loci $\left(\chi^{2}=61.4\right.$, d.f. $\left.=12, P<0.001\right)$, mainly due to variation at the $G P I-2^{*}, A A T-1^{*}, P G M^{*}$ and $P E P L G G^{*}$ loci. Allele frequency plots demonstrate graphically that there was as much variation in frequency of the most common allele at each locus among sites in north Queensland within the latitude $17^{\circ} \mathrm{S}$ to $18^{\circ} \mathrm{S}$ as there was from $12^{\circ} \mathrm{S}$ (Northern Territory) to $24^{\circ} \mathrm{S}$ (southern Queensland) (Fig. 2).

Many uncommon alleles were often widespread. For example, the GPI-2*1 allele was found in north and

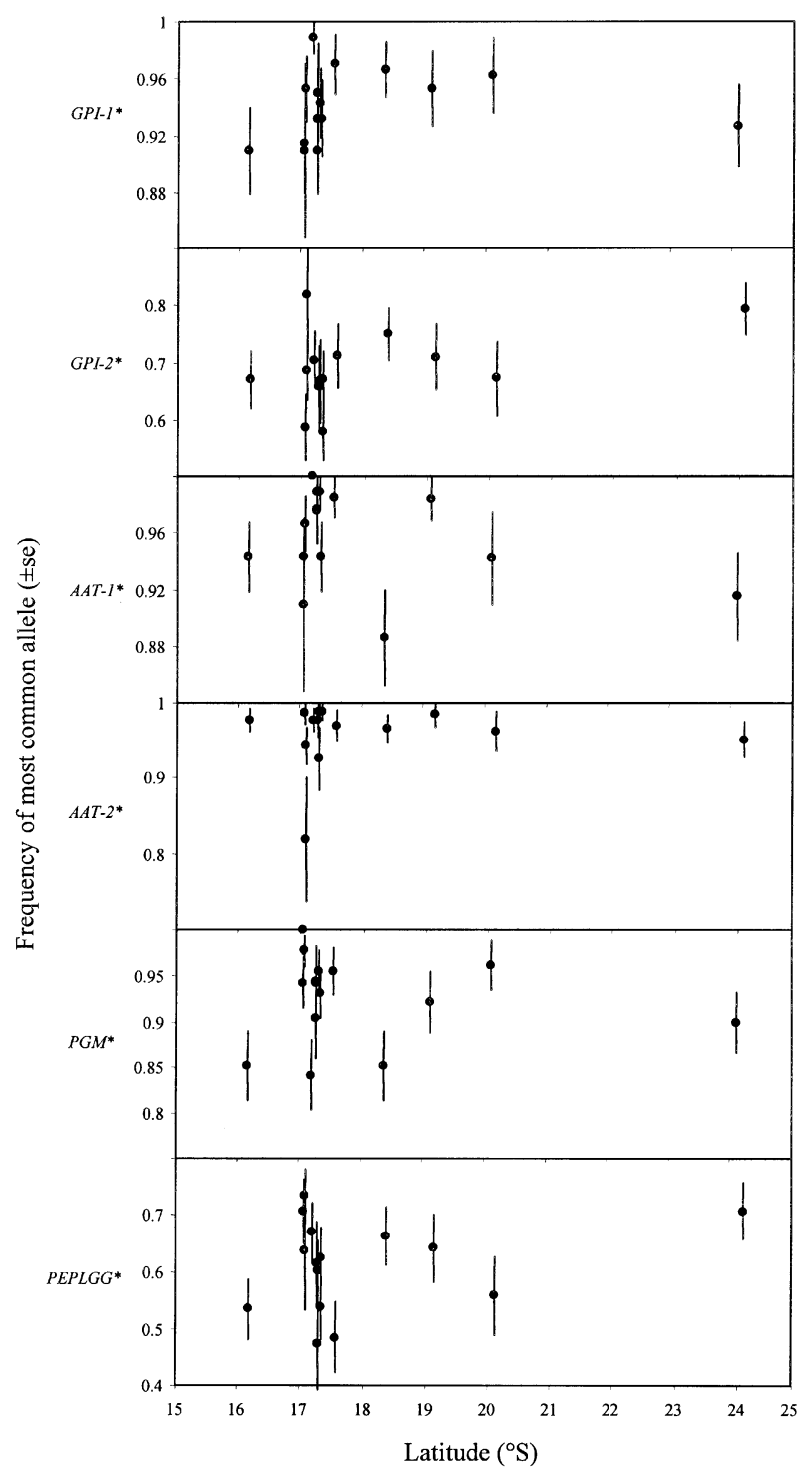

Fig. 2 Frequency of the most common allele ( \pm standard error) for six polymorphic loci of Hypseleotris compressa populations.

south Queensland as well as in Northern Territory populations (Appendix). The two most distant sites, CAL and HWS, shared uncommon alleles at each of the 
six loci. There were only two private alleles (those found at only one location): $A A T-1 * 2$ in the HWS (Northern Territory) and $P G M * 4$ at PYC (Appendix). However, the restricted distribution of these alleles may be attributed to sampling error due to the combination of frequency of the alleles and the sample sizes gathered in the present study.

When all populations of the present study were considered, there were significant associations between $\log \widehat{M}$ and $\log$ coastal distance $\left(P<0.001, r^{2}=0.228\right.$, $y=1.65-0.22 x$ ). However, when only Queensland east coastal sites were considered there was no significant relationship $\left(P>0.05, r^{2}=0.020\right)$.

\section{mtDNA sequencing}

Sequencing of a 567-bp fragment of the ATPase6 mitochondrial gene revealed a high number of haplotypes (18) among the 30 individuals from 10 drainages (haplotype sequences submitted to Genbank, Accession Numbers AF227168-AF227185). There were 37 variable sites, of which four changes were first position $(10.8 \%)$, none were second position and 33 were third position $(89.2 \%)$. The average nucleotide diversity among all unique haplotypes $( \pm \mathrm{SD})$ was 0.009 $( \pm 0.005)$.

A mid-point rooted neighbour-joining tree of unique haplotypes revealed a bushy tree conforming to a star shaped phylogeny (Fig. 3). The relationships among haplotypes were poorly resolved, although there were some relatively divergent haplotypes (e.g. haplotypes E, F, G, H) (Fig. 3). Some haplotypes were widespread (e.g. haplotypes A and C, Table 3). Nevertheless, 14 of the 18 haplotypes occurred only once among the 30 individuals sequenced (Table 3). As mentioned above, a contingency test for differentiation in haplotype frequencies among east coast sites was not significant $(P=0.48)$, although samples sizes were small, which would reduce the power of the test.

Tajima's $D$-test of neutrality of sequence evolution revealed a significant negative value for the 27 sequences from the nine east coastal drainages $(D=-2.19$, $P<0.01)$. This result implies that there were more rare nucleotide site variants than would be expected under a neutral model of evolution (Rand, 1996).

\section{Discussion}

Obligate freshwater fish are expected to display greater levels of genetic differentiation and population subdivision than marine species due to the isolating nature of river systems and small effective population sizes (e.g. Ward et al., 1994). In the present study, allozyme and mtDNA data reveal that the levels of genetic differen-

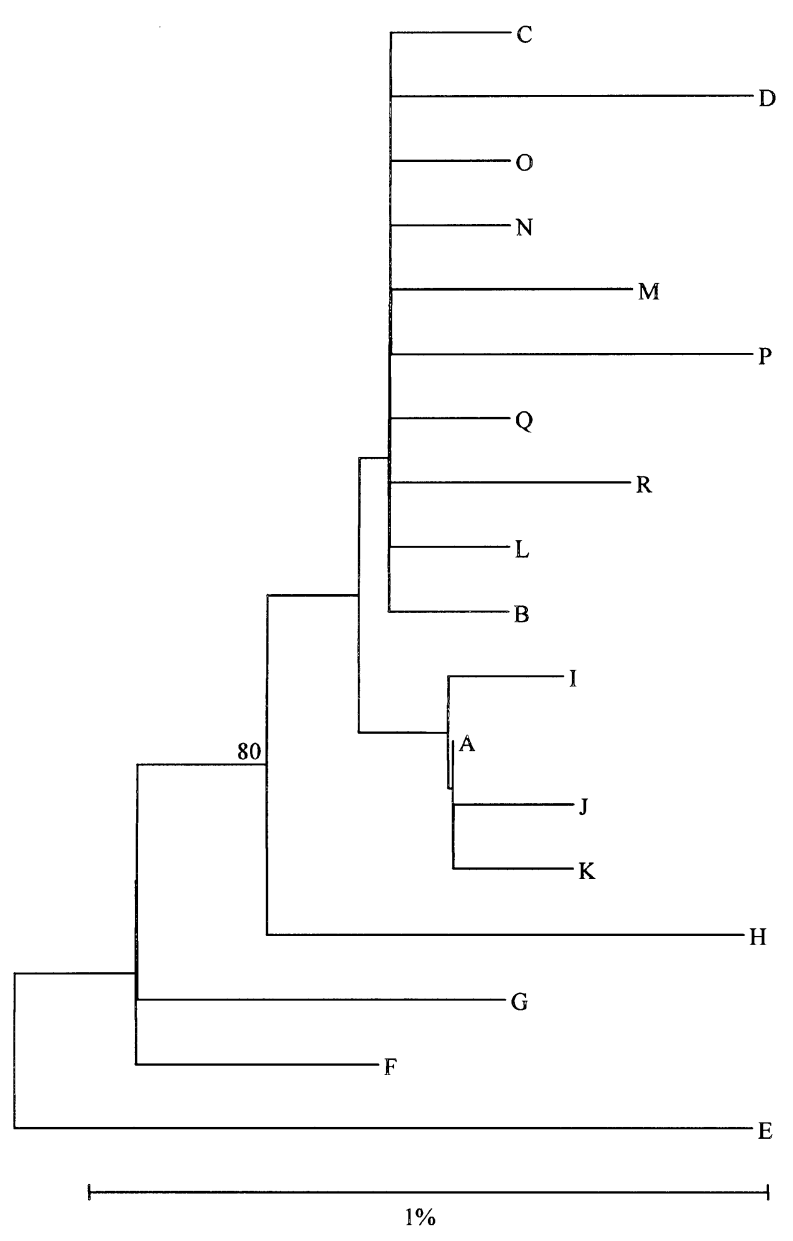

Fig. 3 Mid-point rooted neighbour joining tree (Saitou \& Nei, 1987) showing phylogenetic relationships of $18 \mathrm{mtDNA}$ haplotypes (A-R) of Hypseleotris compressa. The Tamura \& Nei (1993) model of sequence evolution was assumed, with empirically derived gamma distribution alpha parameter of 97 . Values at nodes represent bootstrap confidence levels (1000 replicates) if greater than 50 .

tiation among populations of $H$. compressa, both within and between drainages, were not consistent with these expectations. Although the data suggest that populations of $H$. compressa are not panmictic, the low $F_{\mathrm{ST}}$ estimates suggest that some gene flow among drainages may occur. Hierarchical $F$-statistics reveal that there is little differentiation among populations in different drainages after taking account of the variation within drainages: the differentiation that exists is not partitioned by geography (Table 2). The occurrence of uncommon alleles at either extreme of the sampling range reinforces this notion.

In a scenario in which populations are highly connected, one would expect an isolation by distance effect if the dispersal distance of an individual is less than the range of the species (or the sampling effort) 
Table 3 Distribution of mtDNA haplotypes of a 567-bp fragment of the ATPase6 gene among sequences of Hypseleotris compressa by site and drainage. Site abbreviations as in Table 1 and Fig. 1

\begin{tabular}{|c|c|c|c|c|c|c|c|c|c|c|c|}
\hline \multirow[b]{2}{*}{ Haplotype } & \multicolumn{11}{|c|}{ Site } \\
\hline & STW & RSR & BBD & PYC & BYC & STR & BLW & ELC & CAL & HWS & Total \\
\hline A & 1 & & 1 & & 1 & 2 & 1 & 1 & & & 7 \\
\hline B & 1 & 1 & & & & & & & & & 2 \\
\hline $\mathrm{C}$ & & 1 & & & 2 & & 1 & & 1 & & 5 \\
\hline D & & & & & & & & & & 2 & 2 \\
\hline E & & & & & & & & 1 & & & 1 \\
\hline $\mathrm{F}$ & & & & & & & & & 1 & & 1 \\
\hline G & & & & & & & & & 1 & & 1 \\
\hline $\mathrm{H}$ & & & & & & & & & & 1 & 1 \\
\hline I & 1 & & & & & & & & & & 1 \\
\hline $\mathrm{J}$ & & & 1 & & & & & & & & 1 \\
\hline K & & & & 1 & & & & & & & 1 \\
\hline $\mathrm{L}$ & & & 1 & & & & & & & & 1 \\
\hline M & & & & 1 & & & & & & & 1 \\
\hline $\mathrm{N}$ & & 1 & & 1 & & & & & & & 1 \\
\hline $\mathrm{O}$ & & & & & & & & & & & 1 \\
\hline $\mathrm{P}$ & & & & & & & 1 & & & & 1 \\
\hline Q & & & & & & 1 & & & & & 1 \\
\hline $\mathrm{R}$ & & & & & & & & 1 & & & 1 \\
\hline Total & 3 & 3 & 3 & 3 & 3 & 3 & 3 & 3 & 3 & 3 & 30 \\
\hline
\end{tabular}

(Slatkin, 1993). The present study revealed conflicting relationships between geographical distance and allozyme genetic differentiation, depending on the scale of the comparison. When the population from the Northern Territory (HWS) was included in the analysis, a significant result was obtained; however, when site HWS was omitted from subsequent analyses, there was no apparent relationship. It may be that distance is an important factor in determining the amount of differentiation between eastern and northern Australian populations of $H$. compressa, although the significant association could also be due to a barrier which historically isolated these populations. Because there were no intermediate samples collected between HWS and STW, it is impossible to distinguish between the two scenarios (see, e.g. Stewart et al., 1999).

There are a number of possible explanations as to why there was no relationship between distance and genetic differentiation among east coast populations. First, natural selection cannot be dismissed as a mechanism for homogenizing allele frequencies among sites via balancing selection. Second, the lack of isolation by distance coupled with the low $F_{\mathrm{ST}}$ estimates may imply that there are sufficient rare episodes of long-distance dispersal among $H$. compressa populations to disrupt the formation of an isolation by distance relationship. The mtDNA data revealed a shallow, poorly resolved network, consistent with Avise et al.'s (1987) type II phylogeographic hypothesis that describes a species with a life history conducive to dispersal that also occupies a range free of barriers to gene flow. However, drainages theoretically isolate populations, and such extensive connectivity over such a large range would be unusual for a freshwater fish. Another possible explanation for the lack of an isolation by distance relationship among east coast populations of $H$. compressa might be that they have undergone a demographic change such as a bottleneck or expansion, or both, with insufficient time subsequently for a migration-drift equilibrium to be established.

Patterns of mtDNA variation revealed high allelic diversity, but mostly low sequence divergences (mean nucleotide divergence among unique haplotypes $=$ $0.009 \pm 0.005)$. The significant negative Tajima's $D$ among individuals from east coast sites was probably due to the large number of rare nucleotide site variants. These data are consistent with an historical demographic perturbation. Changes in drainage structure in response to eustatic changes may well have led to considerable demographic changes to $H$. compressa in the past. Sea level changes in the Pleistocene were dramatic and undoubtedly affected the lowland river habitat presently utilized by $H$. compressa. There have been two major increases in sea level, approximately 15000 and 130000 years ago (Chappell, 1983), which would have separated once contiguous drainages and 
shortened the resulting river systems, presumably decreasing the amount of available habitat and possibly decreasing population sizes of $H$. compressa. There may have been opportunities for expansion during the times of lower sea levels between the maxima when systems were again more extensive. Further sampling of mtDNA variation of $H$. compressa may be helpful in refining conclusions about historical demography in this species.

Whatever the equilibrium state of the sampled populations of $H$. compressa, we can still deduce characteristics of its life history and dispersal ability from the genetic data. $H$. compressa does not appear to be a freshwater fish in the classic sense. Many examples in the literature reveal that populations isolated by drainages evolve in isolation, and thus independently (see, e.g. Ward et al., 1994). They display marked gene frequency shifts, extreme sorting of alleles and low within-population variability, and populations in different drainages often have different 'assemblages' of alleles (e.g. McGlashan \& Hughes, 2000). Marine populations are more open and therefore have greater levels of connectedness, often sharing both common and uncommon alleles, and have lower gene frequency differences and higher withinpopulation variability. Populations inhabiting estuaries are often qualitatively midway between those inhabiting freshwater or marine habitats (e.g. Keenan, 1994; Jerry $\&$ Baverstock, 1998). The data of the present study are more consistent with an estuarine or even marine species than one inhabiting freshwater. It may be that there are one or more stages in the life history of $H$. compressa that are, or may recently have been, highly vagile, connecting populations in different drainages and at relatively large geographical scales. If the populations sampled in the present study are not in migration-drift equilibrium, then it is difficult to make any conclusions about the extent of present day gene flow. However, the low levels of genetic subdivision among populations indicated by the allozyme data, the widespread occurrence of some mtDNA haplotypes and the low levels of divergence among other widespread mtDNA haplotypes imply that geographically distant sites have been connected in the past.

There is a deficiency of quantitative information regarding the extent of movement of any life history stage for any hypseleotrid. Juveniles have been reported to migrate en masse from estuarine areas to upstream habitats (Herbert et al., 1995), which is consistent with the genetic data that suggest populations within some drainages are connected. However, this does not explain any of the among-drainage variation, such as that between the Northern Territory and east coast populations. The extent of movement in larval and adult stages is unknown, and without further research into hypsel- eotrid biology and dispersal patterns and rates, identifying which life history stage or stages contribute most to connectivity among drainages is difficult. Recent data reported on the evolutionary genetics of several Hawaiian freshwater gobies may be an informative comparison (Zink et al., 1996; Chubb et al., 1998). It was revealed that the common, but probably independently derived characteristic of amphidromous larvae facilitated gene flow among island populations, there being little phylogeographic signal and no evidence of genetic subdivision. It may be that $H$. compressa, also a gobiid fish, has a dispersive marine larval phase.

Given the hypothesized recent marine ancestry of H. compressa (Allen, 1989) and the genetic evidence of some demographic shift in the recent past, future work may find it useful to explore the history of the freshwater invasion by the hypseleotrid group. Further studies on the macroevolutionary relationships among the widespread genus Hypseleotris may help to reveal if there have been several repeated invasions within the hypseleotrid group, or if freshwater tolerance of all species derived from a single event. Recently, Lee (1999) has explored the phylogenetic and physiological relationships among populations of a euryhaline copepod and found evidence for several repeated invasions across the range of the species. There is thus great potential for further work on Australia's freshwater species, and in conjunction with comparative studies involving representatives from independent lineages, we may gain a greater understanding of the contemporary dynamics and evolutionary history of Australia's freshwater species.

\section{Acknowledgements}

We would like to thank the people that helped with the field collection of samples, especially Dom Loong. Stuart Bunn, Brad Pusey, Mark Kennard, Steve Mackay and Chris Marshall gave valuable advice on the location, abundance, identification and biology of $H$. compressa. We had excellent assistance in the laboratory and fruitful discussions that improved the manuscript with Steve Chenoweth, David Hurwood, Mark Ponniah, David Gopurenko and Cath Cleary. Biff Bermingham kindly supplied unpublished primer sequences ATP8.2 and COIII.2. Michael S. Johnson (University of Western Australia) kindly supplied a computer program that calculated pairwise $G_{\mathrm{ST}}$ values. Michael Arthur helped with statistical and programming concerns. Nick Campbell and two anonymous referees improved earlier versions of the manuscript. The Co-operative Research Centre for Tropical Ecology and Management gave financial assistance via a CRC postgraduate scholarship to DJM. Griffith University contributed postgraduate research funds to DJM. 


\section{References}

ALlen, G. R. 1989. Freshwater Fishes of Australia. T.F.H. Publications Inc., Neptune City.

AUTY, E. H. 1978. Reproductive behaviour and early development of the empire fish Hypseleotris compressus. Aust. J. Mar. Freshwater Res., 29, 585-597.

AVISE, J. C. 1994. Molecular Markers, Natural History and Evolution. Chapman and Hall, New York.

AVISE, J. C., ARNOLD, J., BALL, R. M., BERMINGHAM, E., ET AL. 1987. Intraspecific phylogeny: The mitochondrial DNA gap between population genetics and systematics. Ann. Rev. Ecol. Syst., 18, 489-522.

BEGG, G. A., KeENAN, C. P. AND SELlin, M. J. 1998. Genetic variation and stock structure of school mackerel and spotted mackerel in northern Australian waters. J. Fish. Biol., 53, 465-694.

BELBIN, L. 1995. PATN: Pattern analysis package. CSIRO, Division of Wildlife and Ecology, Canberra.

BERMINGHAM, E., MCCAFFERTY, S. S. AND MARTIN, A. P. 1997. Fish biogeography and molecular clocks: perspectives from the Panamanian Isthmus. In: Kocher, T. D. and Stepien, C. A. (eds) Molecular Systematics of Fishes, pp. 113-128. Academic Press, San Diego.

BURTON, R. S. 1998. Intraspecific phylogeography across the Point Conception biogeographic boundary. Evolution, 52, 734-745.

CHAPPELL, J. 1983. A revised sea-level record for the last 300,000 years from Papua New Guinea. Search, 14, 99-101.

CHENOWETH, S. F., HUGHES, J. M., KEENAN, C. P. AND LAVERY, S. 1998a. When oceans meet: a teleost shows secondary intergradation at an Indian Pacific interface. Proc. R. Soc. $B, 265,415-420$.

CHENOWETH, S. F., HUGHES, J. M., KEENAN, C. P. AND LAVERY, S. 1998b. Concordance between dispersal and mitochondrial gene flow: isolation by distance in a tropical teleost, Lates calcarifer (Australian barramundi). Heredity, 80, 187-197.

CHUBB, A. L., ZINK, R. M. AND FITZSIMONS, J. M. 1998. Patterns of mtDNA variation in Hawaiian freshwater fishes: the phylogeographic consequences of amphidromy. J. Hered., 89, $8-16$.

DOHERTY, P. J., MATHER, P. AND PLANES, S. 1994. Acanthochromis polyacanthus, a fish lacking larval dispersal, has genetically differentiated populations at local and regional scales on the Great Barrier Reef. Mar. Biol., 121, 11-21.

DOHERTY, P. J., PLANES, S. AND MATHER, P. 1995. Gene flow and larval duration in seven species of fish from the Great Barrier Reef. Ecology, 76, 2373-2391.

GYLLENSTEN, U. 1985. The genetic structure of fish: differences in the intraspecific distribution of biochemical genetic variation between marine, anadromous, and freshwater species. J. Fish. Biol., 26, 691-699.

HERBERT, B. W., PEETERS, J. A., GRAHAM, P. A. AND HOGAN, A. E. 1995. Freshwater and Aquatic Habitat Survey of Cape York Peninsula. State of Queensland and the Commonwealth of Australia, Canberra.
HUGHES, J. M., PONNIAH, M., HURWOOD, D. A., CHENOWETH, S. F., ET AL. 1999. Strong genetic structuring in a habitat specialist, the oxleyean pygmy perch Nannoperca oxleyana. Heredity, 83, 5-14.

JERRY, D. R. AND BAVERSTOCK, P. R. 1998. Consequences of a catadromous life-strategy for levels of mitochondrial DNA differentiation among populations of the Australian bass, Macquaria novemaculata. Mol. Ecol., 7, 1003-1013.

JOHNSON, M. S. AND BLACK, R. 1998. Increased genetic divergence and reduced genetic variation in populations of the snail Bembicium vittatum in isolated tidal ponds. Heredity, 80, 163-172.

KEENAN, C. P. 1994. Recent evolution of population structure in Australian barramundi, Lates calcarifer (Bloch): an example of isolation by distance in one dimension. Aust. J. Mar. Freshwater Res., 45, 1123-1148.

KUMAR, S., TAMURA, K. AND NEI, M. 1993. MEGA. Molecular evolutionary genetic analysis, version 1.01. The Pennsylvania State University, University Park, PA.

LARSON, H. K. AND HOESE, D. F. 1996. Family Gobiidae, subfamilies Eleotridinae and Butinae: gudgeons. In: McDowall, R. (ed.) Freshwater Fishes of South-Eastern Australia, 2nd edn, pp. 200-219. Reed Books, Sydney.

LEE, C. E. 1999. Rapid and repeated invasions of fresh water by the copepod Eurytemora affinis. Evolution, 53, 1423-1434.

McElROY, D., MORAN, P., BERMINGHAM, E. AND KORNFIELD, I. 1992. REAP: an integrated environment for the manipulation and phylogenetic analyses of restriction data. J. Hered., 83, 157-158.

McGlashan, D. J. AND HUGHeS, J. M. 2000. Reconciling patterns of genetic variation with stream structure, earth history and biology in the Australian freshwater fish Craterocephalus stercusmuscarum (Atherinidae). Mol. Ecol., 9, 1737-1752.

MUSYL, M. K. AND KEENAN, C. P. 1992. Population genetics and zoogeography of Australian freshwater golden perch, Macquaria ambigua (Richardson 1845) (Teleostei: Percicthyidae), and electrophoretic identification of a new species from the Lake Eyre Basin. Aust. J. Mar. Freshwater Res., 43, $1585-1601$.

MUSYL, M. K. AND KEENAN, C. P. 1996. Evidence for cryptic speciation in Australian freshwater eel-tailed catfish, Tandanus tandanus (Teleostei: Plotosidae). Copeia, 1996, 526-534.

NEI, M. 1973. Analysis of gene diversity in subdivided populations. Proc. Nat. Acad. Sci. U.S.A., 70, 3321-3323.

RAND, D. M. 1996. Neutrality tests of molecular markers and the connection between DNA polymorphism, demography, and conservation biology. Cons. Biol., 10, 665-671.

RAYMOND, M. AND ROUSSET, F. 1995a. An exact test for population differentiation. Evolution, 49, 1280-1283.

RAYMOND, M. AND ROUSSET, F. 1995b. GENEPOP (version 1.2). Population genetics software for exact tests and ecumenicism. J. Hered., 86, 248-249.

RICE, W. R. 1989. Analyzing tables of statistical tests. Evolution, 43, 223-225.

ROBERTSON, A. I. AND BLABER, S. J. M. 1992. Plankton, epibenthos and fish communities. In: Robertson, A. I. and Alongi, 
D. M. (eds) Tropical Mangrove Ecosystems, pp. 173-224. American Geophysical Union, Washington DC.

ROGERS, J. S. 1972. Measures of genetic similarity and genetic distance. Studies in Genetics VII. University of Texas Publications. 7213, 145-153.

ROZAS, J. AND ROZAS, R. 1999. DNASP, version 3: an integrated program for molecular population genetics and molecular evolution analysis. Bioinformatics, 15, 174-175.

SAITOU, N. AND NEI, M. 1987. The neighbor-joining method: a new method of reconstructing phylogenetic trees. Mol. Biol. Evol., 4, 406-425.

SLATKIN, M. 1993. Isolation by distance in equilibrium and non-equilibrium populations. Evolution, 47, 264-279.

Stewart, W. A., DAllas, J. F., Piertney, S. B., MARShall, F., ET AL. 1999. Metapopulation genetic structure in the water vole, Arvicola terrestris, in NE Scotland. Biol. J. Linn. Soc., 68, 159-171.

STRIMMER, K. AND VON HAESELER, A. 1996. Quartet puzzling: a quartet maximum-likelihood method for reconstructing tree topologies. Mol. Biol. Evol., 13, 964-969.

SWOFFORD, D. L. AND SELANDER, R. B. 1989. BIOSYS-1. A computer program for the analysis of allelic variation in population genetics and biochemical systematics. Release 1.7. University of Illinois, Urbana, IL.
TAJIMA, F. 1989. Statistical method for testing the neutral mutation hypothesis by DNA polymorphism. Genetics, 123, 585-595.

TAMURA, K. AND NEI, M. 1993. Estimation of the number of nucleotide substitutions in the control region of mitochondrial DNA in humans and chimpanzees. Mol. Biol. Evol., 10, 512-526.

WARD, R. D., WOODWARK, M. AND SKIBINSKI, O. F. 1994. A comparison of genetic diversity levels in marine, freshwater and anadromous fishes. J. Fish. Biol., 44, 213-232.

WATTS, R. J. 1991. The Effects of Estuaries and Islands on the Genetic Structure of Marine Inshore Fishes. PhD Thesis, The University of Western Australia.

WATTS, R. J., STOREY, A. W., HEBBERT, D. R. AND EDWARD, D. H. E. 1995. Genetic and morphological differences between populations of the western minnow, Galaxias occidentalis, from two river systems in south-western Australia. Mar. Freshwater Res., 46, 769-777.

WRIGHT, s. 1978. Evolution and the Genetics of Populations: Variability Within and Among Natural Populations, vol. 4. The University of Chicago Press, Chicago.

ZINK, R. M., FITZSIMONS, J. M., DITTMAN, D. L., REYNOLDS, D. R., ET AL. 1996. Evolutionary genetics of Hawaiian freshwater fish. Copeia, 1996, 330-335. 


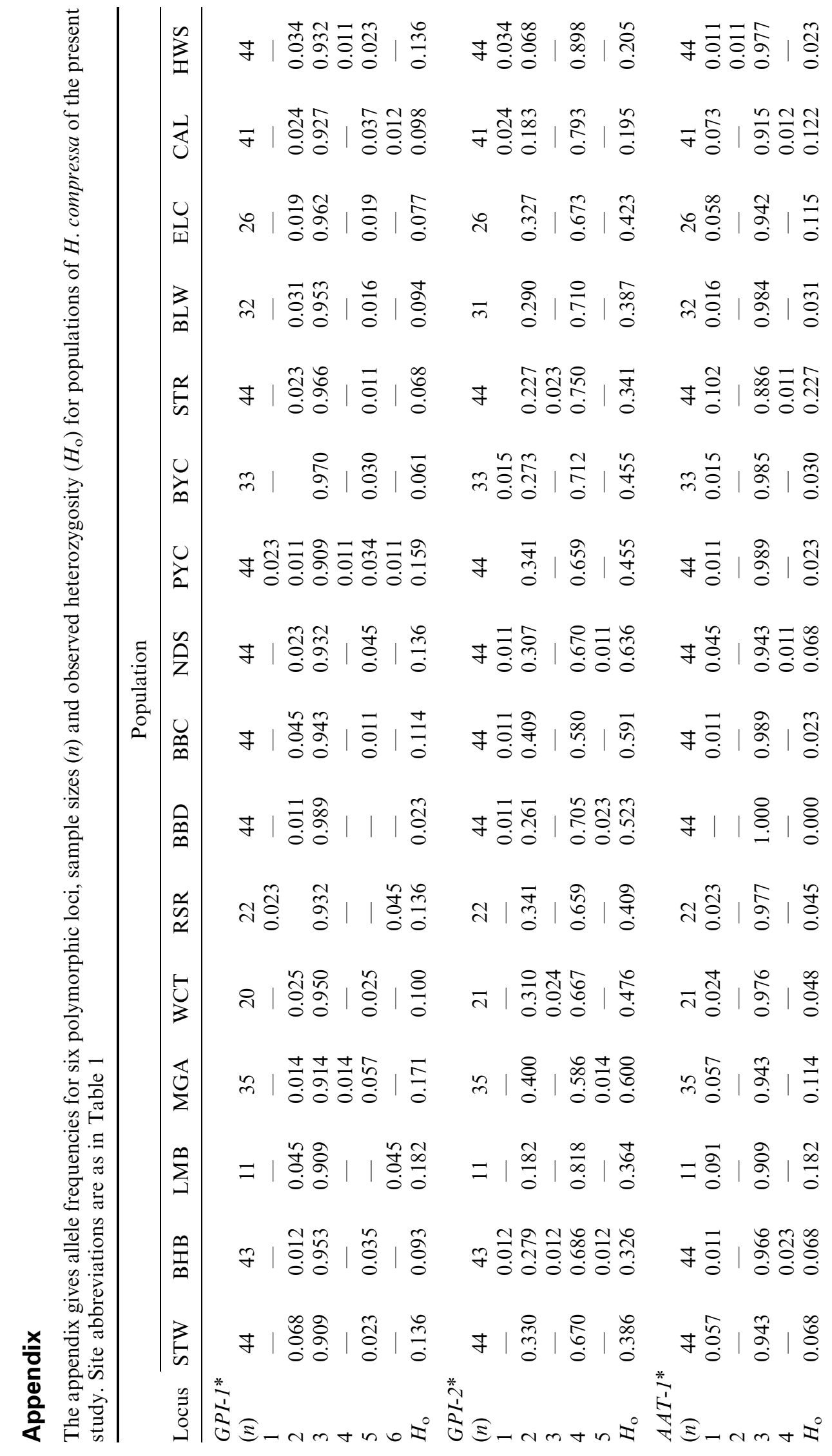

(c) The Genetics Society of Great Britain, Heredity, 86, 222-233. 


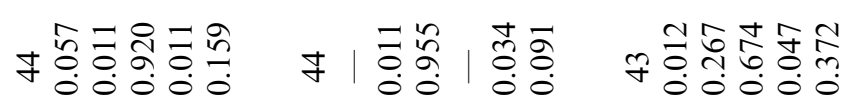

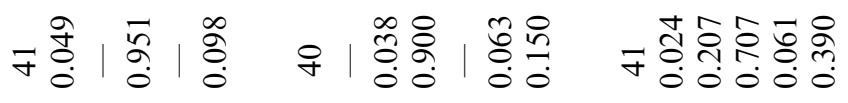

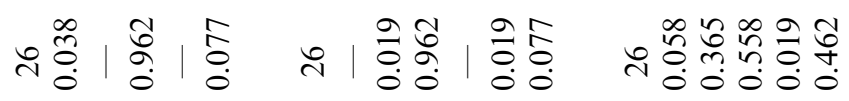

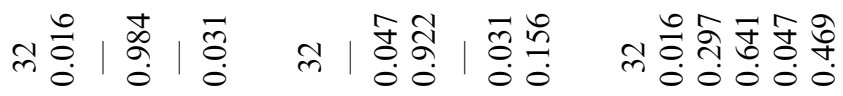

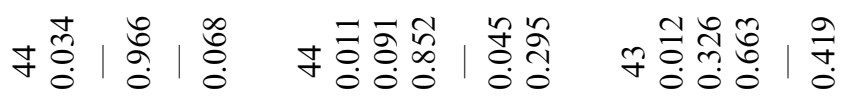

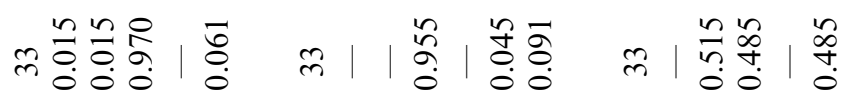

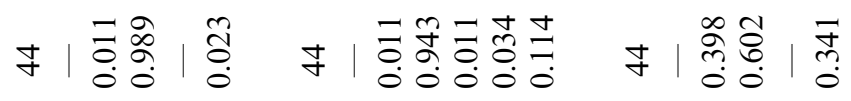

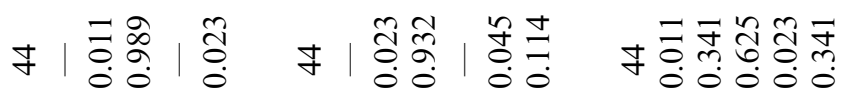

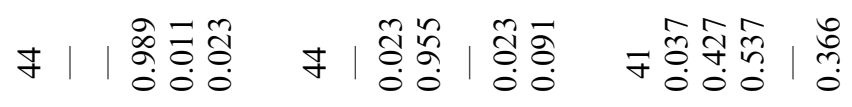

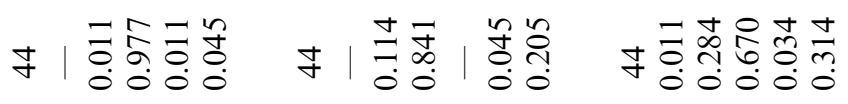

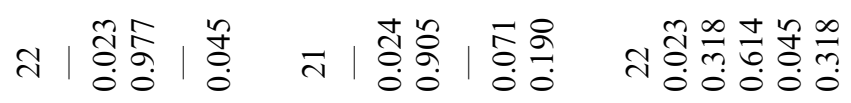

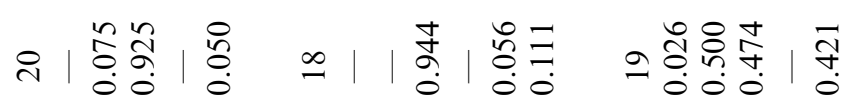
$m \mid \begin{aligned} & \text { m } \\ & 0\end{aligned}$

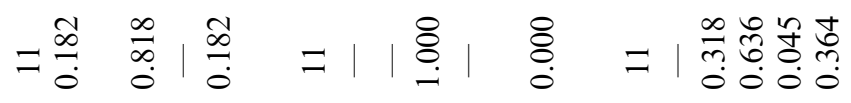

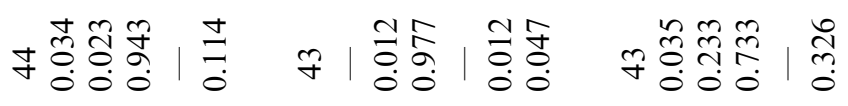

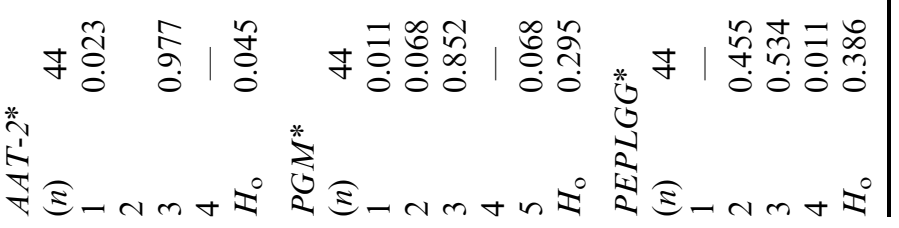

(c) The Genetics Society of Great Britain, Heredity, 86, 222-233. 